\title{
REIVINDICAÇÃO COLETIVA DE DIREITOS, MOVIMENTOS SOCIAIS E REPRESSÃO: AS GREVES DO ABC COMO OBJETO DE ESTUDO
}

SUMÁRIO: Introdução; 1.1 As Greves do ABC: Discursos e História; 20 Movimento Sindical do ABC como Sujeito Coletivo de Direitos; 3 O Estado como Instrumento Opressor, o Direito como Instrumento do Poder Estatal; 4 O Conflito entre o Novo e o Velho: A Repressão e Violência Como Tentativa de Perpetuar Uma Moral Dominante; 5 Conclusão; Referências.

RESUMO: O presente texto analisa o caso das Greves do ABC, ocorridas no final da década de 70 e meados da década de 80 do século passado. $O$ estudo parte de declarações dos líderes sindicais e verifica se o tradicional movimento sindical, em razão da luta pela democracia, transformou-se em um fenômeno que transcendeu a luta de classes para um "novo movimento social". A metodologia utilizada é da revisão bibliográfica e da análise discursiva dos sindicalizados daquele período histórico.

PALAVRAS-CHAVE: Movimentos Sociais; Pluralismo Jurídico; Reivindicação Coletiva de Direitos; Sujeito Coletivo de Direitos.

\section{COLLECTIVE VINDICATION OF RIGHTS, SOCIAL MOVEMENTS AND REPRESSION: THE ABC STRIKES UNDER ANALYSIS}

\begin{abstract}
The late-1970s and mid-1980 ABC strikes are investigated through the declarations of trade union leaders. The analysis verifies whether the traditional trade union movement has transformed itself into a phenomenon that went beyond class struggle towards a new social movement due to the struggle for democracy. The methodology consists of a bibliographical review and the discursive analysis of the members of the trade unions during that historical period.
\end{abstract}

KEY WORDS: Social Movements; Collective Vindication of Rights; Juridical Pluralism; Collective Subject of Rights;

\footnotetext{
Mestre em Direito, Estado e Constituição pela Universidade de Brasília; Especialista em Ciências Penais pela PUC-RS; Advogado e DocenteUniversitário. E-mail: xavierlemos.adv@gmail.com
} 


\section{REIVINDICACIÓN COLECTIVA DE DERECHOS, MOVIMIENTOS SOCIALES Y REPRESIÓN: LAS HUELGAS DEL ABC COMO OBJETO DE ESTUDIO}

RESUMEN: El presente artículo analiza el caso de las Huelgas del ABC, ocurridas en el final de la década de 1970 y comienzos de 1980 , el estudio de las declaraciones de los líderes sindicales y verifica si el tradicional movimiento sindical, en razón de la lucha por la democracia, se transformó en un fenómeno que transcendió la lucha de clases para un nuevo 'movimiento social', la metodología usada es la revisión bibliográfica y el análisis discursivo de los sindicalizados de aquel momento histórico.

PALABRAS-CLAVE: Movimientos Sociales Reivindicación Colectiva de Derechos; Pluralismo Jurídico; Sujeto Colectivo de Derechos.

\section{INTRODUÇÃO}

$\mathrm{O}$ presente texto analisa o caso das Greves do $\mathrm{ABC}$, ocorridas no final da década de 70 e meados da década de 80 do século passado. O campo de análise se dá em cima de fatos apurados na época e principalmente nos pronunciamentos dos líderes sindicais do movimento.

É necessário contextualizar que estas greves aconteceram em épocas de Ditadura Militar, onde o autoritarismo se perpetuava nas mais diversas esferas; dessa forma, os sindicatos, as reuniões de trabalhadores e a greve dentre outros direitos eram suprimidos pelo governo militar.

Trabalharemos aqui com o momento de tensão que advém de uma reivindicação coletiva, que surge de maneira desorganizada em seu princípio, assolada pela opressão de um direito posto que não mais lhe serve, o declínio dessa moral dominante é o que chamaremos de niilismo.

Analisaremos esse momento de ruptura, onde os valores antigos se deterioram, a nova moral se aflora e a forma como as instituições detentoras do poder e, portanto, defensoras dos valores antigos, se comportam frente a essa situação de crise.

Perpassaremos por uma análise filosófica e jurídica desse fenômeno, realizando diálogos entre os fatos da época com autores que demonstram teoricamente os fatos que se comprovaram na prática. 


\subsection{AS GREVES DO ABC: DISCURSOS E HISTÓRIA}

Em uma breve súmula é necessário que se descreva de maneira concisa o contexto histórico da já mencionada Ditadura Militar, mas principalmente o momento de crise econômica vivido pelo país, que se refletia principalmente na classe trabalhadora.

Salários diminutos e exploração excessiva do trabalho, omissão do governo militar quanto às proposições dos operários e negligência do judiciário quanto às demandas dos trabalhadores. Dessa forma vem a eclodir a primeira das Grandes Greves, greve da Scania, que Ricardo Antunes deflagra:

A greve tinha sido uma engenhosidade da espontaneidade operária. Sem vislumbrar outra alternativa para a obtenção de suas reivindicações, os metalúrgicos buscaram, através da sua experiência, a opção que poderia reverter a negativa e a intransigência patronal. ${ }^{1}$

É necessário explicitar que não houve uma pré-organização e pretensão à greve, foi algo espontâneo, motivado pela exploração sofrida pelos trabalhadores, bem explicita o líder sindical Luiz Inácio "Lula" da Silva:

$\mathrm{O}$ arrocho salarial fez com que a classe trabalhadora brasileira, após muitos anos de repressão, fizesse o que qualquer classe trabalhadora no mundo faria: negar sua força de trabalho as empresas. Era a única forma que os operários tinham de recuperar o padrão salarial, ou melhor, entrar no caminho de sua recuperação. ${ }^{2}$

Nessa expressão do líder do movimento sindical começa a explicitar-se a decadência dos valores que procuramos detectar posteriormente com base na filosofia niilista.

A pretensão pela filosofia niilista se dá em face de estudarmos o decair de valores, a mudança, a transição de algo que se considerava como válido para algo que não mais serve, gerando um vazio, um espaço. Explicitando a questão niilista, Franco Volpi argumenta que:

El nihilismo es, por lo tanto la situación de desorientación que aparece una vez que fallan las referencias tradicionales o sea, los ideales y los valores que representaban la respuesta al para qué?, y que como tales iluminaban el actuar del hombre. $^{3}$

\footnotetext{
1 ANTUNES, Ricardo. A Rebeldia do Trabalho, O Confronto Operário no ABC Paulista: as Greves de 1978/80. 2. ed., p. 22.

3 VOLPI, Franco. El nihilismo. Buenos Aires: Biblios, 2005, p. 16.
} 
Trata-se do caso em pauta, uma vez que o poder vigente em época anterior ainda era suportado, mesmo que em razão da repressão, mas também em consequência dos trabalhadores subordinarem-se à forma de organização do trabalho, não se encontrando ainda com esse forte choque de valores que evidencia o momento niílico.

Posteriormente a este vazio, começa a reivindicação do novo, a derrubada do velho e o embate com o antigo, gerando tensão, explicando as fases da desconstrução de valores, com base nas palavras de Friedrich Nietzsche:

Período da Obscuridade: tentativas de todos os gêneros para conservar o antigo e não deixar o novo escapar-se.

Período da Claridade: percebe-se que o antigo e o novo são antíteses fundamentais: os valores antigos nascem da vida decrescente; os novos, da vida ascendente.

Observa-se que o ideal antigo é ideal contrário à vida (nascido da decadência e determinando a decadência, embora adornado com as esplêndidas roupagens domingueiras da moral).

Compreendemos as coisas antigas e não somos suficientemente fortes para as novas.

Período das três grandes paixões: o desprezo, a compaixão, a destruição.

Período da catástrofe: a vinda de uma doutrina que passa os homens pelo crivo, que impulsiona os fracos às decisões, e também os fortes. ${ }^{4}$

Esses períodos são fortemente detectados quando Antunes analisa as greves:

A luta contra a opressão e o despotismo fabril, que aflorava aqui de maneira bastante embrionária, apesar de seu estatuto de secundariedade nesta ação concreta, inseria-se no processo de denúncia e combate da superexploração do trabalho, uma vez que o despotismo e a opressão exprimiam a forma pela qual, no cotidiano fabril, a exploração do trabalho se efetivava. E o arrocho salarial era a manifestação mais perversa desta concretude. ${ }^{5}$

E segue Luiz Inácio da Silva: "Esses são movimentos espontâneos que nasceram da necessidade que o trabalhador tem de respirar". O que se denota desses fatos é que o ser humano, aqui representado pelo sujeito coletivo de direito, quando oprimido, sufocado, não tendo outra forma de fazer valer sua condição humana acaba por rebelar-se.

\footnotetext{
4 NIETZSCHE, Friedrich. Vontade de Potência, Parte 1. São Paulo: Scala, p. 205.

5 ANTUNES, Ricardo. 1992, p. 33.

6 Idem, p. 33.
} 
$\mathrm{O}$ que anteriormente lhe prendia, fossem as normas institucionais, fosse a repressão, ou a própria dinâmica laboral, acabaram tornando-se secundárias quando não mais conseguiu sentir-se dignamente humano; dessa forma, os valores que antes serviam de freio para suas ações acabam por esvaírem, gerando a rebelião.

Em primeiro prisma ela é descontrolada, impulsiva, em face da desconstrução das certezas, no entanto, posteriormente ao vazio niílico, acaba formando novos valores, e reivindicando algo que antes não lhe era claro.

\section{O MOVIMENTO SINDICAL DO ABC COMO SUJEITO COLETIVO DE DIREITOS}

Antes de encontrar a conexão entre os sujeitos coletivos de direito e o movimento sindical do $\mathrm{ABC}$, é necessário que tracemos a definição teórica do que podemos ou não considerar como sujeito coletivo de direitos e novos movimentos sociais.

Os novos movimentos sociais fazem parte de um processo de singularidades reivindicando transformações e potencializando suas demandas.

$O$ relevante para a utilização da noção de sujeito, na designação dos movimentos sociais, é a conjugação entre o processo das identidades coletivas, como forma do exercício de suas autonomias e a consciência de um projeto coletivo de mudança social a partir das próprias experiências?.

Esses movimentos sociais detectados pelo autor configuram as massas coletivas ajuntadas em processos de transformação. A respeito dos sujeitos coletivos, o autor Wolkmer aponta que:

Portanto, os novos sujeitos coletivos aqui tratados não são quaisquer movimentos sociais momentâneos e pouco estruturados, de reivindicação ou de protesto, mas aquelas estruturas sociais mais permanentes e estáveis que corporificam uma nova forma de fazer política. Trata-se de "novos movimentos sociais" que reúnem um conjunto de características comuns, unidas por uma lógica organizacional "democrático-coletivista" composta pela identidade de "objetivos", "valores", "formas de ação" e "atores sociais". Critérios que permitem qualificá-los como "novos" para distingui-los das antigas práticas reivindicatórias imediatistas

\footnotetext{
SOUSA JR., José Geraldo de. Movimentos Sociais - Emergência de Novos Sujeitos: o sujeito coletivo de direito. In: SOCIOLOGIA Jurídica: Condições Sociais e Possibilidades Teóricas. Porto Alegre: Sergio Antonio Fabris, 2002, p. 57.
} 
de ação coletiva. O "novo" refere-se à ação consciente e responsável posta em movimento, representada por grupos associativos e comunitários, como os movimentos dos "sem-terra" (rural e urbano), dos negros, das mulheres, dos direitos humanos, dos ecólogos, dos pacifistas e dos religiosos (Comunidades Eclesiais de Base). O "novo" está no fato de se tratar de manifestações com capacidade de surgir "fora" da cena política institucional, fundadas em razões que não só transcendem os estreitos interesses de produção e consumo, mas, sobretudo, compõem nova identidade coletiva, capaz de romper com a lógica do paradigma social dominante e se libertar das formas opressoras de manipulação e cooptação, criando alternativas implementadoras de práticas democráticas participativas ${ }^{8}$.

Portanto, fica clara a ideia do que são esses novos sujeitos históricos, como o autor os denomina. São, dessa forma, múltiplos, organizados, livres, autodeterminados, que se emancipam a partir de um processo de libertação democrática e participativa. Podemos encontrá-los perfeitamente na figura das greves do $\mathrm{ABC}$. Herrera Flores traz uma importante reflexão sobre as lutas sociais e os processos de luta pela dignidade:

En definitiva, cuando hablamos de derechos humanos como productos culturales antagónicos a las relaciones capitalistas, lo hacemos del "resultado histórico del conjunto de procesos antagonistas al capital que abren o consolidan espacios de lucha por la dignidad humana". En primer lugar, pues, destaca la frase "resultado del conjunto de procesos antagonistas", con la que queremos reforzar el carácter histórico-dinámico de los procesos sociales y jurídicos que permiten abrir y, a su vez, garantizar lo que resulte de las luchas sociales por la dignidad. En segundo lugar, hablamos de "espacios de lucha", es decir, de la construcción de las condiciones necesarias para llevar adelante propuestas alternativas al orden existente y a la "Ideología-Mundo" de carácter básicamente abstracto y descontextualizado. Y, en tercer lugar, nos referimos a la "dignidad humana". Con ello no nos estamos refiriendo a una concepción de la dignidad que imponga unos determinados contenidos a cualquier forma de vida que luche cotidianamente por sus expectativas y sus necesidades ${ }^{9}$.

É importante trazer também a interpretação de Boaventura de Sousa Santos acerca desses movimentos sociais, figuras que expressam uma alteração do status

8 WOLKMER, Antonio Carlos. Pluralismo Jurídico: fundamentos de uma nova cultura no Direito. 3. ed. rev. e atual. São Paulo: Alfa Omega, 2001, p. 138.

9 FLORES, Herrera J. Los derechos humanos como productos culturales. Crítica del humanismo abstracto. Catarata, 2005a, p. 247. 
quo, uma transformação social maior, o que nos parece claro no exemplo que procuramos explorar.

Las formas de opresión y de exclusión contra las cuales luchan no pueden, en general, ser abolidas con la mera concesión de derechos, como es típico de la ciudadanía; exigen una reconversión global de los procesos de socialización y de inculcación cultural y de los modelos de desarrollo, o exigen transformaciones concretas, inmediatas y locales (por ejemplo, el cierre de una central nuclear, la construcción de una guardería infantil o de una escuela, la prohibición de publicidad violenta en la televisión), exigencias que, en ambos casos, van más allá de la mera concesión de derechos abstractos y universales ${ }^{10}$.

É interessante situar esse processo dos movimentos sociais como afirmativa dos direitos como lutas pelo acesso a condições, às quais permitam a sensação de dignidade. É inegável, pois, que a divisão social existente, negando acesso igualitário a bens e serviços, aflora a necessidade de lutar. Então define essa figura como sujeito histórico coletivo:

$\mathrm{Na}$ verdade, o "novo sujeito histórico coletivo" articula-se em torno "do sofrimento - às vezes centenário - e das exigências cada vez mais claras de dignidade, de participação, de satisfação mais justa e igualitária" das necessidades humanas fundamentais de grandes parcelas sociais excluídas, dominadas da sociedade. ${ }^{11}$

As categorias excluídas do processo, inconformadas com o posto, lutam por transformações. Externam sua inconformidade e, em decorrência, mudam a realidade. Dessa forma, ainda definindo esses movimentos sociais, Wolkmer demonstra que:

Portanto, os novos sujeitos coletivos aqui tratados não são quaisquer movimentos sociais momentâneos e pouco estruturados, de reivindicação ou de protesto, mas aquelas estruturas sociais mais permanentes e estáveis que corporificam uma nova forma de fazer política. Trata-se de "novos movimentos sociais" que reúnem um conjunto de características comuns, unidas por uma lógica organizacional "democrático-coletivista" composta pela identidade de "objetivos", "valores", "formas de ação" e "atores sociais". Critérios que permitem qualificá-los como "novos" para distingui-los das antigas práticas reivindicatórias imediatistas de ação coletiva. O "novo" refere-se à ação consciente e responsável posta em

\footnotetext{
${ }_{10}$ SANTOS, Boaventura de Sousa. Los Nuevos Movimientos Sociales. Revista OSAL no 5, CLACSO, Buenos Aires, 2001, p. 181.

${ }^{11}$ WOLKMER, 2001, p. 138.
} 
movimento, representada por grupos associativos e comunitários, como os movimentos dos "sem-terra" (rural e urbano), dos negros, das mulheres, dos direitos humanos, dos ecólogos, dos pacifistas e dos religiosos (Comunidades Eclesiais de Base). O "novo" está no fato de se tratar de manifestações com capacidade de surgir "fora" da cena política institucional, fundadas em razões que não só transcendem os estreitos interesses de produção e consumo, mas, sobretudo, compõem nova identidade coletiva, capaz de romper com a lógica do paradigma social dominante e se libertar das formas opressoras de manipulação e cooptação, criando alternativas implementadoras de práticas democráticas participativas. ${ }^{12}$

Tal afirmativa faz-se imperiosa quando o autor define a qualidade desse sujeito coletivo apresentado nos movimentos sociais, que é a democracia e o coletivo, bem como sua confissão de reivindicação, mas não como modo individual e sim como quem reclama em nome do grupo, o que seria então o fator de novidade, por manifestarem-se de grupos não usuais, distintos dos grupos políticos tradicionais. Avança, ainda, caracterizando figuras exemplificativas do que considera como esses novos movimentos sociais:

Para os quais as "novas identidades" compõem uma constelação de múltiplas subjetividades coletivas, aglutinando:

a) os camponeses sem-terra, os trabalhadores agrícolas, os emigrantes rurais;

b) os operários mal remunerados e explorados;

c) os subempregados, os desempregados e trabalhadores eventuais;

d) os marginalizados dos aglomerados urbanos, subúrbios e vilas, carentes de bens materiais e de subsistência, sem água, luz, moradia e assistência médica;

e) as crianças pobres e menores abandonados;

f) as minorias étnicas discriminadas;

g) as populações indígenas ameaçadas e exterminadas;

h) as mulheres, os negros e os anciãos que sofrem todo tipo de violência e discriminação;

i) finalmente, as múltiplas organizações comunitárias, associações voluntárias e movimentos sociais reivindicativos de necessidades e direitos. $^{13}$ 
É preciso compreender esse primeiro extrato da teoria de Wolkmer, pois selecionando de onde possa surgir esse direito plural é que poderemos entender o Movimento operário. Não longe dessa compreensão, Herrera Flores caracteriza quem são esses sujeitos e explica o que é sua compreensão da luta desses agentes sociais organizados:

Y, finalmente (contextualizada) ya que no podemos entender los derechos sin verlos como parte de la lucha de grupos sociales empeñados en promover la emancipación humana por encima de las cadenas con las que se sigue encontrando la humanidad en la mayor parte de nuestro planeta. Los derechos humanos no sólo se logran en el marco de las normas jurídicas que propician su reconocimiento, sino también, y de un modo muy especial, en las prácticas sociales de ONGs, de Asociaciones, Movimientos Sociales, de Partidos Políticos, de Iniciativas Ciudadanas y reivindicaciones de grupos, sean minoritarios (indígenas) e no (mujeres) que de un modo u otro han quedado tradicionalmente marginados del proceso de positivación y reconocimiento institucional de sus expectativas. Contextualizar los derechos como prácticas sociales concretas nos facilitaría ir contra la homogeneización, invisibilización, centralización y jerarquización de las prácticas institucionales tradicionales. Estaríamos ante $\mathrm{u}$ intervencionismo humanitarista llevado a cabo por los propios actores sociales, una guerra de baja intensidad humanitaria contra un orden desigual en el que 200 personas poseen más de 175.000 millones de peseta» mientras que los 582 millones de habitantes de los 43 países menos desarrollados sólo llegan a 146.000, y contra un orden genocida en el que el analfabetismo o la falta de acceso al agua potable afectan a 1.000 millones de personas, en el que 250 millones de niños son explotados laboralmente y en el que 30.000 niños en el mundo mueren cada día por enfermedad evitables (Informe sobre el Desarrollo Humano 2000 , Fuente ONU). No hay duda, la indiferencia es el efecto de la complicidad. ${ }^{14}$

Nesse mesmo patamar, o autor avança na questão dos direitos humanos como forma de empoderamento, pretendendo uma vida digna:

$\mathrm{Y}$, en un sentido marcadamente social, los derechos humanos son el resultado de luchas sociales y colectivas que tienden a la construcción de espacios sociales, económicos, políticos/jurídicos que permitan el empoderamiento de todas $\mathrm{y}$ todos para poder luchar plural y diferencialmente por una vida digna de ser vivida. En otros términos, especificamos los derechos desde una perspectiva pragmática y de fuerte contenido social..$^{15}$

\footnotetext{
${ }_{14}$ FLORES, Joaquin Herrera. El vuelo de Anteo. Derechos humanos y crítica de la razón liberal. Bilbao: Editorial Desclée de Brouwer, 2000, p. 46.

15 FLORES, 2005a, p. 247.
} 
Boaventura de Sousa Santos explica uma questão que difere os novos movimentos sociais dos movimentos tradicionais, que seriam os próprios movimentos operários, que seriam lutas por democracia, subjetividade; vejamos alguns trechos do autor:

La novedad más grande de los NMSs reside en que constituyen tanto una crítica de la regulación social capitalista, como una crítica de la emancipación social socialista tal como fue definida por el marxismo. Al identificar nuevas formas de opresión que sobrepasan las relaciones de producción, y ni siquiera son specíficas de ellas, como son la guerra, la polución, el machismo, el racismo o el productivismo; y al abogar por un nuevo paradigma social, menos basado em la riqueza y en el bienestar material del que, en la cultura y en la calidad de vida, denuncian los NMSs, con una radicalidade sin precedentes, los excesos de regulación de la modernidad. Tales excesos alcanzan no sólo el modo como se trabaja y produce, sino también el modo como se descansa y vive; la pobreza y las asimetrías de las relaciones sociales son la otra fase de la alienación y del desequilibrio interior de los individuos; y finalmente, esas formas de opresión no alcanzan específicamente a una clase social y sí a grupos sociales ${ }^{16 "}$.

E porque, então, enquadramos o Movimento Operário do $\mathrm{ABC}$, na figura de Novo Movimento Social, quando um dos grandes estudiosos desses movimentos dignifica o movimento operário como não integrante desses "novos movimentos"?

É, pois, por um outro raciocínio do autor que podemos fundamentar nosso raciocínio de inclusão do movimento do operário do $\mathrm{ABC}$ como "novo" movimento social. O autor português avança na descrição desses novos sujeitos coletivos de direito:

Uno de los más encendidos debates sobre los NMSs incideen el impacto de éstos en la relación subjetividad-ciudadanía. Según algunos, los NMSs representan la afirmación de la subjetividad frente a la ciudadanía. La emancipación por la que luchan no es política sino ante todo personal, social y cultural. Las luchas en que se traducen se pautan por formas organizativas (democracia participativa) diferentes de las que precedieron a las luchas por la ciudadanía (democracia representativa). Al contrario de lo que sedio con el dúo marshalliano ciudadanía-clase social en el período del capitalismo organizado, los protagonistas de estas luchas no son las 
clases sociales, son grupos sociales, a veces mayores, a veces menores que las clases, con contornos más o menos definidos en función de intereses colectivos, a veces muy localizados pero potencialmente universalizables. ${ }^{17}$

Resta, pois, determinado que os novos movimentos sociais têm por características lutas que vão além da luta de classe, do operário contra o empregador, o que analisando o fenômeno do $\mathrm{ABC}$ por um paradigma meramente superficial nos faria concluir pela lógica classista.

É a característica desse sujeito explicitado nos movimentos sociais, que sua característica democrática e o coletivismo, e a reivindicação, mas não como caráter individual e sim grupal, o que seria então novo, por manifestarem-se de grupos políticos não usuais.

Ocorre, porém, que a conotação política da Ditadura Militar, do movimento das "Diretas Já", de um contexto de um povo em busca de sua liberdade política, acabou dando às Greves do $\mathrm{ABC}$ uma conotação que foi além da luta classista. As greves tomaram uma conotação de luta pela democracia, seja pelo lado dos grevistas, seja pela ótica da atitude repressiva do governo militar.

Assim sendo, não podemos compreender o movimento sindical do $\mathrm{ABC}$ como meramente operário, mas sim como uma luta universal, pela democracia, o que o torna um "novo movimento social".

\section{O ESTADO COMO INSTRUMENTO OPRESSOR, O DIREITO COMO INSTRU- MENTO DO PODER ESTATAL}

Partindo para o presente ponto de análise é importante elucidar como o direito vigente pode convalidar um governo opressivo, quando este não se faz da vontade de seus cidadãos, característica fundante dos governos autoritários.

Nesse sentido, Paolo Grossi deflagra essa visão autoritária de direito:

Porque ao homem comum de hoje o direito aparece sob dois aspectos que não contribuem propriamente para transformá-lo em algo bem aceito: vem-lhe do alto e de longe, como se fosse uma telha que cai de um teto sobre a cabeça de um passante; mostra-se a ele como poder, como comando autoritário, evocando imediatamente a imagem desagradabilíssima do juiz e do funcionário da polícia, com ulterior possibilidade de sanções e coerções. ${ }^{18}$

\footnotetext{
${ }_{17}$ Idem, p. 180.

${ }^{18}$ GROSSI, Paolo. Primeira Lição Sobre Direito. Rio de Janeiro: Forense, 2006, p. 2.
} 
Confirma-se tal perspectiva quando Antunes elucida decisão do Tribunal Regional do Trabalho à época, que inflamou a perspectiva dos grevistas:

Foi realizado então, sob pressão do regime, um segundo julgamento da greve, onde se aguardava a declaração de sua ilegalidade, para que se tivesse "pretexto legal" para se desencadear toda a ação do aparato repressivo. E tudo ocorreu em conformidade com sua programação: o TRT invalidou o primeiro julgamento e decretou a ilegalidade do movimento. ${ }^{19}$

Trata-se claramente do que Paolo Grossi afirma, um Direito que não mais serve, que busca preservar uma moral autoritária em conformidade com os planos dos detentores do poder, o Direito passa a ser instrumento político, ou seja, deixa de fluir da relação entre os homens e serve somente para afirmar aquele que domina. $\mathrm{E}$ assim, o autor italiano, segue:

O Estado, enquanto entidade tendencialmente totalizante, realiza-se na mais rigorosa compacidade, qualidade que obtém (que quer a todo custo obter) graças ao instrumento unilateral da intolerância. O Estado, fechado na sua insularidade, dialoga somente com o exterior e somente com outras entidades estatais similares; no seu interior limita-se simplesmente a ditar as condições em base às quais uma regra deixa o confuso limbo das regras meramente sociais e se torna jurídica; a inobservância das condições tem um contragolpe sem piedade: a ilicitude e, se tudo andar bem, e se o Estado não considera muito turbada a própria ordem pública, a irrelevância. $^{20}$

Dessa forma, se entende da decisão do TRT que os grevistas eram então ilícitos, não desejados e nocivos ao bom andamento do Estado, condição que foi bem detectada pelos líderes sindicais:

Estão jogando tudo contra o nosso movimento. Estão lutando contra os trabalhadores como se fôssemos inimigos da pátria, ladrões e assassinos. Patrões, polícia, governo, tribunais, rádio, televisão, jornal, tudo enfim, é utilizado para massacrar homens e mulheres que pacificamente lutam por reivindicações reconhecidamente justas. ${ }^{21}$

A partir dessa compreensão o fenômeno do direito como forma de opressão já se dá detectado e surge então a insubordinação, a rebeldia como meio de afirmação de um novo valor. Nesse sentido, temos uma declaração do líder sindical

\footnotetext{
19 ANTUNES, 1992, p. 70.

20 GROSSI, 2006, p. 30.

21 ANTUNES, 1992, p. 70.
} 
do movimento, Antunes (p. 46) - "Lula afirmou: A greve pode ser considerada ilegal, porém ela é justa e legítima, pois sua ilegalidade é baseada em leis que não foram feitas por nós ou por nossos representantes".

Neste ponto essencial, destaca-se a quebra com o vigente, o momento onde efetivamente os grevistas deram-se conta que o direito posto não mais lhe servia, que somente a luta por aquilo que acreditavam ser o justo era necessária, o que Nietzsche chama de momento da catástrofe, onde o novo tem que surgir.

Assim sendo, se faz necessário citar Henry David Thoreau: "Não é desejável cultivar pela lei o mesmo respeito que cultivamos pelo direito. A única obrigação que tenho o direito de assumir é a de fazer a qualquer tempo aquilo que considero direito." 22

As semelhanças entre os ideais do filósofo e do líder sindical no momento específico em pauta são muito grandes. Dessa forma sucedeu o instante de afirmação das greves como reivindicação do direito novo, o que naturalmente gerou um embate.

\section{O CONFLITO ENTRE O NOVO E O VELHO: A REPRESSÃO E VIOLÊNCIA COMO TENTATIVA DE PERPETUAR UMA MORAL DOMINANTE}

No presente ponto analisaremos a repressão policial e a violência como forma de contraposição às greves, característica basilar de Estados autoritários, que no caso em pauta se deflagrou de forma intensa.

Passada a análise da decadência dos valores, da rebeldia e proposição do novo, faz-se necessária analisar a resposta do governo militar às greves do $\mathrm{ABC}$.

Utilizaremos mais uma vez da interlocução dos fatos da época com autores que trabalham o poder estatal autoritário. Nesse sentido, Nietzsche aponta que:

Da mesma forma o Estado, o domínio em todos os seus ramos pelos funcionários e soldados: da mesma forma a ciência, para poder trabalhar confiança e economizar suas forças. Fazem então triunfar aqui a moral comum, porque, por meio dela, realiza um avanço; e para lhe assegurar a vitória guerreiam e empregam a violência contra a imoralidade de acordo com que "direito". Sem nenhum direito: mas de conformidade com o instinto de conservação. ${ }^{23}$

${ }^{23}$ NIETZSCHE, Friedrich. Vontade de Potência: parte 2. São Paulo: Scala, p. 201. 
Aqui se faz clara a questão da imposição da violência como meio de conservação de uma moral dominante, tratando-se claramente do acontecido nas Greves do ABC conforme assevera Antunes:

Em conformidade com a lógica arquitetada para o enfrentamento da greve, decretou-se, no dia 17 de abril, a intervenção dos Sindicatos operários de São Bernardo e Santo André e destituiu-se suas respectivas direções, cassando seus direitos sindicais. Dois dias após, numa ação vultosa e rápida, foram presos Lula e diversos líderes do movimento, além de dirigentes sindicais e membros representantes das associações liberais. ${ }^{24}$

Ricardo Antunes desenvolve a questão da greve de uma forma muito semelhante:

O cerco do capital e do seu aparato estatal-repressivo intensificava-se: a cada assembleia realizada, onde se afirmava a continuidade da greve, mais líderes eram presos, ao mesmo tempo em que, pela proibição de utilização das praças públicas, diminuía significativamente o contingente operário nas assembleias gerais. ${ }^{25}$

Quando trata a questão da violência, Walter Benjamim vai trazê-la como fim e como meio, elucidando que quando ela se dá como meio, ela funda ou conserva direitos, no entanto quando ela se dá por um fim, ela renuncia por si só toda sua validade. $^{26}$

No mesmo caminho, vai trabalhar com a questão da função da polícia a serviço do direito vigente:

La policía es un poder con fines jurídicos (con poder para disponer), pero también con la posibilidad de establecer para sí misma, dentro de vastos límites, tales fines (poder para ordenar). El aspecto ignominioso de esta autoridad -que es advertido por pocos sólo porque sus atribuciones en raros casos justifican las intervenciones más brutales, pero pueden operar con tanta mayor ceguera en los sectores más indefensos y contra las personas sagaces a las que no protegen las leyes del estado - consiste en que en ella se ha suprimido la división entre violencia que funda y violencia que conserva la ley. Si se exige a la primera que muestre sus títulos de victoria, la segunda está sometida a la limitación de no deber proponerse nuevos fines. ${ }^{27}$

\footnotetext{
${ }_{24}$ ANTUNES, 1992, p. 70.

${ }^{25}$ ANTUNES, 1992, p. 70.

${ }^{26}$ BENJAMIM, Walter. Para una Crítica de La Violencia. p. 8.

${ }^{27}$ Idem, p. 8-9.
} 
Desse ponto de vista, conseguimos elucidar a questão da violência policial como aparato para manutenção do poder, aquela que limita os que propõem novos fins. Ainda acerca do poder policial, Walter Benjamim nos diz que:

La policía es un poder que funda - pues la función específica de este último no es la de promulgar leyes, sino decretos emitidos con fuerza de ley - y es un poder que conserva el derecho, dado que se pone a disposición de aquellos fines. La afirmación de que los fines del poder de la policía son siempre idénticos o que se hallan conectados con los del derecho remanente es profundamente falsa. Incluso "el derecho" de la policía marca justamente el punto en que el estado, sea por impotencia, sea por las conexiones inmanentes de todo ordenamiento jurídico, no se halla ya en grado de garantizarse - mediante el ordenamiento jurídico - los fines empíricos que pretende alcanzar a toda costa. Por ello la policía interviene "por razones de seguridad" en casos innumerables en los que no subsiste una clara situación jurídica cuando no acompaña al ciudadano, como una vejación brutal, sin relación alguna con fines jurídicos, a lo largo de una vida regulada por ordenanzas, o directamente no lo vigila. ${ }^{28}$

Nota-se que pelos conceitos do presente autor, a violência arbitrária utilizada pelo governo militar foge ao que ele considera como uma violência justa, onde seria o caso de conservação de um direito ou até em razão de segurança. No entanto, era claro o intuito pacífico dos manifestantes grevistas, sua reivindicação era de direitos e garantias, sem utilizar-se de armas e/ou violência. Ocasiona, pois, que por mais que a ordem vigente tente se portar como vigente, o tempo irá deflagrar seu desgaste, válido mencionar Thoureau acerca do tema:

Se a injustiça faz parte do atrito necessário à máquina do governo, deixemos que assim seja: talvez amacie com o passar do tempo, e certamente a máquina irá se desgastar. Se a injustiça tem uma mola, polia, cabo ou manivela exclusivamente para si, talvez possamos questionar se o remédio não será pior que o mal. Mas se ela for de natureza tal que exija que nos tornemos agentes de injustiça para com os outros, então proponho que violemos a lei. ${ }^{29}$

Desse modo, ao responder de forma abrupta ao direito coletivo que se insurgia, acaba tornando-se uma violência injusta, razão que é explicada por Albert Camus quando trata dos sistemas autoritários, no caso específico do nazismo, porém, com as devidas proporções, que se encaixa no perfil do caso em pauta:

\footnotetext{
28 Idem, Ibidem.

29 THOREAU, 2009, p. 26.
} 
O Estado identifica-se com o "aparelho", isto é, com o conjunto de mecanismos de conquista e repressão. A conquista dirigida para o interior do país chama-se propaganda ("o primeiro passo em direção ao inferno disse Frank") ou repressão. Dirigida para o exterior, cria o exército. Todos os problemas são, dessa forma, militarizados, colocados em termos de poderio e de eficácia. ${ }^{30}$

Em consonância com Walter Benjamim, o autor argelino aborda a questão do poder de polícia em regimes autoritários, pois explicita que esses governos, em verdade, acabam militarizando todas as questões da vida pública. Tornam, portanto, todas e quaisquer ameaças a seu poder uma questão bélica, considerando todo e qualquer cidadão inconformado como um inimigo, que deve ser vencido e aniquilado, e por isso acabaram não só agredindo como também prendendo as lideranças do movimento grevista.

Dessa forma, a tendência é a de conflitos campais, formação de piquetes e repressão policial, quando o novo busca seu espaço e o velho tenta manter-se a todo custo, o último resquício é a violência, seja ela justa ou injusta. A tensão iminente é explicitada inúmeras vezes na história e no caso em pauta flagra-se de forma concisa.

\section{CONSIDERAÇÕES FINAIS}

$\mathrm{O}$ presente trabalho visou alguns pontos do processo grevista do final da década de 70 e começo dos 80 . Buscamos uma análise do momento de desconstrução de verdades, de conceitos e moral, demonstrando através de opiniões da época como isso se evidenciou.

Em primeiro prisma ocorre o processo de opressão, que gera um desconforto, um incômodo, que acarreta em um processo de reflexão e de posterior ação.

Ao iniciar essa ação contrária ao abuso, os valores antigos vão decaindo, e as antigas verdades se tornam obsoletas, o movimento que antes se configura desorganizado politicamente, começa a energizar-se e consolidar suas diretrizes. Posteriormente, é necessário mencionar a afirmação de seus valores, a reivindicação de seus direitos frente à exploração e inércia do poder dominante quanto às vontades do sujeito coletivo reivindicante.

Já consolidado, o movimento se torna massificado, gerando uma série de greves no país, ocasionando alterações no dia a dia do governo vigente. Através do

\footnotetext{
${ }_{30}$ CAMUS, Albert. O homem revoltado. 5. ed. São Paulo: Record, 2003, p. 213.
} 
uso do direito para deflagrar uma ilegalidade, passa o poder dominante a endurecer a possibilidade do novo. É o instante do conflito aqui trabalhado.

Esse necessário conflito, tensão que faz criar, acaba ocasionando em ações cada vez mais enérgicas dos dois polos da relação: o movimento grevista e a ditadura militar. Assim sendo, o governo militar utiliza-se da repressão e, posteriormente, da violência para reprimir os manifestantes. Como bem explicitado, é a forma que governos autoritários têm para manter a ordem vigente.

O uso do aparato repressivo e violento pode ter sucesso em curta duração, no entanto, quando esse poder já não reflete mais a vontade do povo (seja pela forma de governo, ou então pelo objeto de análise, o direito), as manifestações tornam-se contínuas, massivas e constantes.

O caso em pauta nos demonstra claramente isso, com o passar dos anos, em não prolongado espaço de tempo, a ditadura militar e sua normativa opressora, seu autoritarismo, representado pela repressão e violência acabaram perdendo suas forças.

Em suma, o caso de análise foi o das Greves do $\mathrm{ABC}$, no entanto, a temática evidencia-se em diversos fatos ocorridos na história da civilização. Quando o direito não mais é respeitado, quando um valor não é mais anuído, a mudança faz-se imponente, é um processo que não mais tem volta.

Quando o sujeito coletivo organiza-se e reivindica a mudança, por não deixar escravizar-se pelo opressor, altera-se a ordem posta. Remetemo-nos aqui a inúmeros autores que trabalham teoricamente essa afirmativa, e o caso em pauta deflagra na prática aquilo que de forma teórica os mais variados autores de diferentes épocas e áreas buscaram elucidar.

\section{REFERÊNCIAS}

AGUIAR, Roberto A. R. Direito, Poder e Opressão. 3. ed. São Paulo: Alfa-Ômega, 1990.

ANTUNES, Ricardo. A Rebeldia do trabalho, o confronto operário no ABC Paulista: as Greves de 1978/80. 2. ed. Campinas: Alvorada, 1992.

BENJAMIM, Walter. Para una Crítica de La Violencia. Edición Electrónica de Escuela de Filosofía Universidad ARCIS. 
BENJAMIM, Walter. Critique of Violence in Reflections, Essays, Aphorisms, Autobiographical Writings. New York: Ed. Shochen Books.

BOITO, Jr. A.; NORONHA, E.; RODRIGUES, I. J.; RODRIGUES, L. M.; NOVAES, R. R. O Sindicalismo Brasileiro nos Anos 80. São Paulo: Paz e Terra.

CAMUS, Albert. O homem revoltado. 5. ed. São Paulo: Ed. Record, 2003.

GROSSI, Paolo. Primeira Lição Sobre Direito. Rio de Janeiro: Forense, 2006.

FLORES, Joaquin Herrera. El vuelo de Anteo. Derechos humanos y crítica de la razón liberal. Bilbao: Desclée de Brouwer, 2000.

FLORES, Joaquin Herrera. De habitaciones propias y otros espacios negados: Una teoría crítica de las opresiones patriarcales. Bilbao: Universidad de Deusto, 2005.

FLORES, Joaquin Herrera. Los derechos humanos como productos culturales: crítica del humanismo abstracto. Catarata, 2005a.

FLORES, Joaquin Herrera. Introducción General. In: MOURA, Marcelo Oliveira de. Irrompendo no Real: Escritos de Teoria Crítica dos Direitos Humanos. Pelotas: Educat, 2005b.

FLORES, Joaquin Herrera. La verdad de una Teoría Crítica de los Derechos Humanos. In: MOURA, Marcelo Oliveira de. Irrompendo no Real: Escritos de Teoria Crítica dos Direitos Humanos. Pelotas: Educat, 2005c.

FLORES, Joaquin Herrera. Manifesto Inflexivo. In: MOURA, Marcelo Oliveira de. Irrompendo no Real: Escritos de Teoria Crítica dos Direitos Humanos. Pelotas: Educat, 2005d.

FLORES, Joaquin Herrera. A re(invenção) dos direitos humanos. Florianópolis: Fundação Boiteux, 2009.

NIETZSCHE, Friedrich. Vontade de Potência. Parte 1. São Paulo: Scala, [19--].

NIETZSCHE, Friedrich. Vontade de Potência. Parte 2. São Paulo: Scala, [19--]. 
NIETZSCHE, Friedrich. Assim Falou Zaratustra. São Paulo: Rideel, 2005.

NIETZSCHE, Friedrich. Escritos sobre Direito. Rio de Janeiro: Ed. da PUC-Rio, 2009.

NIETZSCHE, Friedrich. A Genealogia da Moral. Petrópolis: Vozes, 2009.

NIETZSCHE, Friedrich. O Nascimento da Tragédia. São Paulo: Schwarcz, 1992.

NIETZSCHE, Friedrich. A Gaia Ciência. São Paulo: Martin Claret, 2004.

RUBIO, David Sánchez. Contra uma cultura Anestesiada de Derechos Humanos. San Luis Potosí: Facultad de Derecho de la Universidad Autónoma de San Luis Potosí, 2007.

RUBIO, David Sánchez. Pluralismo jurídico e emancipação social. In: WOLKMER, Antonio Carlos; VERAS NETO, Francisco Q.; LIXA, Ivone M. (Org.). Pluralismo Jurídico: os novos caminhos da contemporaneidade. São Paulo: Saraiva, 2010.

RUBIO, David Sánchez; HERRERA FLORES, Joaquín; CARVALHO Salo de. Direitos humanos e globalização: fundamentos e possibilidades desde a teoria crítica. Porto Alegre: EdiPUCRS, 2010.

SANTOS, Boaventura de Sousa. The Law of the Oppressed: The Construction and Reproduction of Legality in Pasárgada. Source: Law \& Society Review, v. 12, n. 1, autumn, 1977.

SANTOS, Boaventura de Sousa. Notas sobre a história jurídico-social de Pasárgada. 1987. Disponível em: < http://www.dhnet.org.br/direitos/militantes/ boaventura/boaventura1d.html $>$.

SANTOS, Boaventura de Sousa. O discurso e o poder: ensaio sobre a sociologia da retórica jurídica. Porto Alegre: Fabris, 1988.

SANTOS, Boaventura de Sousa. Los Nuevos Movimientos Sociales. Revista OSAL, $\mathrm{n}^{\circ}$ 5, CLACSO, Buenos Aires. 2001.

SANTOS, Boaventura de Sousa. Introdução a uma ciência pós-moderna. 4. ed. São Paulo: Graal, 2003. 
SANTOS, Boaventura de Sousa. Poderá o direito ser emancipatório? Revista Crítica de Ciências Sociais, Coimbra, n. 65, maio, 2003.

SANTOS, Boaventura de Sousa. (Org.). Conhecimento prudente para uma vida decente: "um discurso sobre as ciências revisitado". São Paulo: Cortez, 2006.

SANTOS, Boaventura de Sousa. Um discurso sobre as ciências. 6. ed. São Paulo: Cortez, 2009.

SANTOS, Boaventura de Sousa. A crítica da razão indolente: contra o desperdício da experiência: para um novo senso comum: a ciência, o direito e a política na transição paradigmática. 7. ed. São Paulo: Cortez, 2009b.

SANTOS, Boaventura de Sousa. Renovar a Teoria Crítica: e reinventar a emancipação social. São Paulo: Boitempo, 2009.

SANTOS, Boaventura de Sousa. Pela Mão de Alice: o social e o político na pósmodernidade. 13. ed. São Paulo: Cortez, 2010.

SANTOS, Boaventura de Sousa. Para uma Revolução Democrática de Justiça. São Paulo: Cortez, 2011.

SOUSA JÚNIOR, José Geraldo de. Para uma crítica da eficácia do direito: anomia e outros aspectos fundamentais. Porto Alegre: Fabris, 1984.

SOUSA JÚNIOR, José Geraldo de. Movimentos Sociais - Emergência de Novos Sujeitos: o sujeito coletivo de direito. In: SOCIOLOGIA Jurídica: Condições Sociais e Possibilidades Teóricas. Porto Alegre: Sergio Antonio Fabris, 2002.

SOUSA JÚNIOR, José Geraldo de. Introdução crítica ao direito agrário. Brasília: Editora Universidade de Brasília, 2002. (Série O Direito Achado na Rua).

SOUSA JÚNIOR, José Geraldo de. Jornal do SINDJUS. a. XV, n. 33, p. 3, jul. 2006.

SOUSA JÚNIOR, José Geraldo de. (Org.). Educando para Direito Humanos: pautas pedagógicas para a cidadania na universidade. Porto Alegre: Síntese, 2004.

SOUSA JÚNIOR, José Geraldo de. Idéias para a Cidadania e para a Justiça. Porto Alegre: Sergio Antonio Fabris, 2008. 
SOUSA JÚNIOR, José Geraldo de. Direito como Liberdade: O Direito Achado na Rua Experiências Populares Emancipatórias de Criação do Direito. 338f. Tese (Doutorado) - Universidade de Brasília, 2008.

SOUSA JÚNIOR, José Geraldo de. Introdução crítica ao direito à saúde. Brasília: Cead/UnB, 2008. (Série O Direito Achado na Rua).

SOUSA JÚNIOR, José Geraldo de. Direito como liberdade: o direito achado na rua. Porto Alegre: Sergio Antonio Fabris, 2011.

SOUSA JÚNIOR, José Geraldo de; SANT'ANNA, Alayde. Direito achado na rua(o). Brasília: Ed. da UnB, 1987. (Curso de Extensão Universitária a Distância).

SOUSA JÚNIOR, José Geraldo de; AGUIAR, Roberto A. R. de (Org.). Introdução crítica ao direito do trabalho. Brasília: Ed. da UnB, 1993. (Série O Direito Achado na Rua).

THOREAU, Henry David. A desobediência civil. Porto Alegre: L\&PM, 2009.

TOURAINE, Alain. Crítica da Modernidade. 7. ed. Petrópolis. Rio de Janeiro: Vozes, 1994.

VOLPI, Franco. El nihilismo. Buenos Aires: Biblios, 2005.

WOLKMER, Antonio Carlos. Pluralismo Jurídico: fundamentos de uma nova cultura no Direito. $3^{\mathrm{a}}$ ed. rev. e atual. São Paulo: Alfa Omega, 2001.

WOLKMER,AntonioCarlos. Pluralismojurídico, direitoshumanoseinterculturalidade. Revista Sequência, n. 53, p. 1-16, dez. 2006.

WOLKMER, Antonio Carlos. Pluralismo Jurídico: Fundamentos de una nueva cultura del derecho. Sevilla: Mad, 2006.

WOLKMER, Antonio Carlos. Introdução ao Pensamento Jurídico Crítico. 7. ed. São Paulo: Saraiva, 2009.

WOLKMER, Antonio Carlos. Pluralismo e crítica do constitucionalismo na América Latina. In: SIMPÓSIO NACIONAL DE DIREITO CONSTITUCIONAL, 9. Anais... 
WOLKMER, Antonio Carlos. Pluralismo Jurídico: Nuevo marco emancipatório en América Latina. In: RANGEL, Jesús Antonio de la Torre. Pluralismo Jurídico: teoria y Experiências. México: Centro de Estudios Jurídicos y Sociales P Enrique Gutiérrez, 2007.

Recebido em: 27 de julbo de 2013

Aceito em: 10 de setembro de 2015 